\title{
Rapid revegetation by sowing seed mixtures of shrub and herbaceous species
}

\author{
J. Feng ${ }^{1, *}$, C. Zhang ${ }^{2, *}$, T. Zhao ${ }^{1}$, and Q. Zhang ${ }^{3}$ \\ ${ }^{1}$ College of Soil and Water Conservation, Beijing Forestry University, Beijing 100083, China \\ ${ }^{2}$ Beijing Key Lab of Industrial Land Contamination and Remediation, Environmental Protection \\ Research Institute of Light Industry, Beijing 100089, China \\ ${ }^{3}$ Lvbao Landscape Design Institute of Shanxi, Shanxi 030006, China \\ *These authors contributed equally to this work.
}

Correspondence to: T. Zhao (zhtning@bjfu.edu.cn)

Received: 12 January 2015 - Published in Solid Earth Discuss.: 23 January 2015

Revised: 9 April 2015 - Accepted: 24 April 2015 - Published: 21 May 2015

\begin{abstract}
Fast revegetation by means of sowing seed mixtures of shrub and herbaceous species is a measure to prevent bare soils from wind and water erosion. A field experiment was used to test the effect of species selection and the ratio of shrub to herbaceous species on vegetation formation and shrub growth. Results showed that herbaceous species hastened cover formation and maintained a high coverage for a longer period. However, the growth of shrubs was hindered. In the North China Plain or where the soil and climate are similar, the ratio of shrub to herbaceous seeds is proposed to be $6: 4-7: 3$ (weight ratio). Among the herbaceous species tested, Festuca arundinacea Schreb. grows relatively slow, so it should be mixed with other fast-growing species in the practice of rapid revegetation, and a seeding density lower than $6 \mathrm{~g} \mathrm{~m}^{-2}$ is proposed when applied; Orychophragmus violaceus O. E. Schulz. wilts when the seeds are ripe, leading to a significant decrease of coverage, so other species with different phenology should be involved when it is applied; Viola philippica Car. is a good ground cover plant which grows fast and maintains a stable coverage from July to October, and a seeding density of $1.5 \mathrm{~g} \mathrm{~m}^{-2}$ is proposed for rapid revegetation. Herbaceous species have different traits. Three different types of herbs were found in our experiment: slowgrowing stable species (F. arundinacea), fast-growing unstable species $(O$. violaceus $)$ and fast-growing stable species $(V$. philippica). Shrubs, slow-growing stable species and fastgrowing unstable species should not be used alone because they cannot cover the ground fast or they cannot maintain a long period of good coverage. A small seeding rate of fast-
\end{abstract}

growing stable species should be used to ensure a fair coverage against erosion. Because natural environmental conditions are heterogeneous and stochastic, more species should be added to enhance the stability of plant community.

\section{Introduction}

Development and construction projects often cause damage to native vegetation. In abandoned quarries or surface mines, recolonization of plants is very difficult (Ballesteros et al., 2012) because of the destruction of natural soil structure and seed bank, as well as the limitation of nutrition and water (Jim, 2001; Haritash et al., 2007). Even though technical restoration can accelerate succession, it takes decades to achieve a complex self-sustainable ecosystem (Zhang et al., 2013). During the succession, wind or water erosion may occur when the vegetation coverage is still low, further decreasing soil nutrient (Zuazo and Pleguezuelo, 2008) and thus hindering the process of revegetation (Wang et al., 2005). Geologic hazards may also happen if no protective measures are applied (Robbins et al., 2013). Heavy metals in mineral waste may be transported by wind force and cause soil pollution (Brotons et al., 2010). Besides, during construction of roads and buildings, temporary dumps without covering may be eroded, resulting in soil loss.

Soil covering is a useful measure to protect soil from wind and water erosion (Mu, 2010), where vegetation plays an important role (Sterk, 2003). The risk and intensity of wind and 
Table 1. Some chemical properties of the local soil used in the field experiment.

\begin{tabular}{lllll}
\hline $\begin{array}{l}\text { Organic matter } \\
\left(\mathrm{g} \mathrm{kg}^{-1}\right)\end{array}$ & $\begin{array}{l}\text { Total N } \\
\left(\mathrm{g} \mathrm{kg}^{-1}\right)\end{array}$ & $\begin{array}{l}\text { Available N } \\
\left(\mathrm{mg} \mathrm{kg}^{-1}\right)\end{array}$ & $\begin{array}{l}\text { Available K } \\
\left(\mathrm{mg} \mathrm{kg}^{-1}\right)\end{array}$ & $\begin{array}{l}\text { Available P } \\
\left(\mathrm{mg} \mathrm{kg}^{-1}\right)\end{array}$ \\
\hline 4.72 & 2.47 & 19.06 & 22.23 & 4.74 \\
\hline
\end{tabular}

water erosion decrease with increased vegetation cover (Cai, 2001; Maurer et al., 2009; Kefi et al., 2011; Houyou et al., 2014). Plants increase soil surface roughness, decrease wind speed and as a result the erosivity and erodibility decrease (Borrelli et al., 2014). Plants increase concentration time during rainfall events and increase infiltration, so less runoff is produced.

Different types of vegetation respond differently to wind and water erosion. Trees with large canopy are more effective in reducing wind speed, whereas shrubs are more effective in trapping transporting materials (Leenders et al., 2007). Compared to herbaceous species, shrubs have more developed root systems to improve soil structure and conserve water in deep layers, resulting in a better effect on soil and water conservation (Huang et al., 2006; Wei et al., 2009), and its effect is less affected by rain intensity compared to herbs (Zhang et al., 2014). Trees develop slowly (Ji et al., 2011) and have limited effect on soil protection during the early stage of development (Zhang and Shao, 2003), while herbs germinate and grow fast, rapidly covering the ground to prevent splash erosion and decrease runoff (Franklin et al., 2012).

Seed mixtures of shrubs and grasses take the advantage of both taxons, but the competition for light, water and nutrition may affect vegetation cover formation (Milton and Dean, 1995) and thus the effect of soil protection. As shown by some research, the competition from grasses might cause severe growth decline of woody plants, especially during their early stage of development (Gordon et al., 1989; Denslow et al., 2006). Because the interaction between woody species and herbaceous species is complicated, it was proposed that traits such as niche breadth and competitiveness for different resources of different species should be thoroughly studied, and the selection of species should be based on environmental condition including soil, water and light (Heneghan et al., 2008; Abe et al., 2015; Oliveira et al., 2014). By means of species selection and controlling seeding density, a positive effect can be attained for shrub establishment (Franklin et al., 2012).

In this research, a measure of fast revegetation by means of sowing seed mixtures of shrub and herbaceous species was tested using field experiment. We focused on (1) which seed mixtures of shrub and grass (which species and what proportion) could provide a fair or good coverage for a long period; (2) how different proportions of species affect the speed of cover formation and the stability of coverage (specifically, we tested the effect of the ratio of shrub to herbaceous seeds, $R_{\mathrm{S} / \mathrm{h}}$ ); and (3) how different herbaceous species affect the growth of shrub. Based on our research, advice will be proposed on species selection and determination of their proportion in seed mixtures during the practice of revegetation in (1) plains where wind erosion occurs, (2) gentle slopes where water erosion occurs and plant growth is not significantly affected by the slope and (3) seriously degraded sites such as abandoned mines where measures such as topsoil covering have been applied to improve soil quality.

\section{Materials and methods}

\subsection{Study area}

The research was conducted in the Ecological Restoration Research Base of Environmental Protection Research Institute of Light Industry (EPRILI), located in Changping County, Beijing $\left(40^{\circ} 9^{\prime} 56.73^{\prime \prime} \mathrm{N}, 116^{\circ} 9^{\prime} 1.04^{\prime \prime} \mathrm{E}, 57 \mathrm{~m}\right.$ a.s.l.). Beijing has a continental monsoon climate with a rainy season from June to September. The mean annual precipitation is $620 \mathrm{~mm}$ (historical data). Monthly precipitation and average temperature during the experimental period were measured using Davis Vantage Pro2 Weather Station, and the data are shown in Fig. 1.

The study area was a flatland. The local soil used for the experiment was sandy loam. The $\mathrm{pH}$ value was 7.44 . The chemical properties of the soil are shown in Table 1 (Liang, 2013).

\subsection{Experimental design}

Four native species were studied, including a shrub species, Amorpha fruticosa L., and three herbaceous species, Festuca arundinacea Schreb., Viola philippica Car. and Orychophragmus violaceus O. E. Schulz. These species are commonly seen in the North China Plain, and former research has shown their tolerance against water or nutrient deficiency. The characters of target species are shown in Table 2 and the designs of seed mixtures are shown in Table 3.

Every design of the seed mixtures was tested in a $4.5 \mathrm{~m}$ long, $1.3 \mathrm{~m}$ wide plot, so there were altogether 41 plots. Seed mixtures with a seeding density of $15 \mathrm{~g} \mathrm{~m}^{-2}$ were manually sowed without fertilizer in May 2013. Non-woven fabrics (a planar, permeable, polymeric textile material) were used as soil cover to protect the seeds from erosion and enhance humidity. Irrigation was applied until mid-June, after which precipitation became the only water source for plants. 
Table 2. Characteristics of target species.

\begin{tabular}{llll}
\hline Species & Family & Life form & Average size \\
\hline A. fruticosa & Leguminosae & deciduous shrub & $1-4 \mathrm{~m}$ \\
F. arundinacea & Gramineae & cool-season perennial C $\mathrm{C}_{3}$ species of bunchgrass & $30-100 \mathrm{~cm}$ \\
O. violaceus & Cruciferae & annual or biennial herbs & $15-60 \mathrm{~cm}$ \\
V. philippica. & Violaceae & perennial herbs & $4-14 \mathrm{~cm}$ \\
\hline
\end{tabular}

Table 3. Designs of seed mixtures.

\begin{tabular}{|c|c|c|}
\hline No. & Species & Ratio by mass \\
\hline $\mathrm{T} 1$ & A. fruticosa: F. arundinacea & $\begin{array}{l}0: 10,1: 9,2: 8,3: 7,4: 6,5: 5,6: 4,7: 3 \\
8: 2,9: 1\end{array}$ \\
\hline $\mathrm{T} 2$ & A. fruticosa: O. violaceus: V. philippica & $\begin{array}{l}\text { The ratio of shrub to herbs was the same with } \\
\mathrm{T} 1 \text {, and the masses of } O \text {. violaceus and } \\
\text { V. philippica were the same. }\end{array}$ \\
\hline $\mathrm{T} 3$ & A. fruticosa: O. violaceus & The design of $\mathrm{T} 3$ was the same with $\mathrm{T} 1$. \\
\hline $\mathrm{T} 4$ & A. fruticosa: V. philippica & The design of $\mathrm{T} 4$ was the same with $\mathrm{T} 1$. \\
\hline T0 & A. fruticosa & \\
\hline
\end{tabular}

Note: the thousand-grain weight of A. fruticosa, F. arundinacea, O. violaceus and V. philippica are 6.163, 2.814, 2.175 and $0.981 \mathrm{~g}$, respectively. Each plot is denoted as $\mathrm{T} x \mathrm{t} y$. The capital letter T indicates species, and the following $x$ ranges from 0 to 4 , indicating different combinations of species. The small letter $t$ indicates the proportion of shrub seeds, and the following $y$ ranges from 0 to 9 , indicating the percentage of $A$. fruticosa in the seed mixtures by mass, which equals $y / 10$. Data of T2t0 are deleted because of deficient setting of the experimental plot.

\subsection{Data collection and analysis}

From July to October 2013 , three $1 \times 1 \mathrm{~m}^{2}$ sample plots were randomly taken in each plot three times a month to measure the coverage of $A$. fruticosa and the total coverage of all species. Invaded native species were recorded. The same measurement was also made from April to August 2014. In this study, a coverage of $60 \%$ was assumed to be fair, and a coverage of $80 \%$ was assumed to be good, because erosion risk was low in slopes under $30^{\circ}$ with a fractional vegetation cover of 60-80\% based on an erosion model (Vrieling et al., 2006). The duration of total coverage higher than 60 and $80 \%$ were calculated by the following equation.

Duration of fair or good coverage $=$

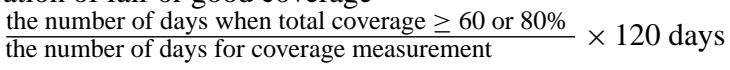

Coefficient of variation (CV) of total coverage during the experimental period was calculated to describe the stability of total vegetation coverage. Each $\mathrm{CV}$ value of different $R_{\mathrm{S}}$ h was taken as a sample, and the Friedman test for nonparametric paired samples was used to test the significance of variation between the $\mathrm{CV}$ values of different combinations of shrub and herbaceous species.

At the end of October 2013, 15 individuals of A. fruti$\cos a$ in each plot were randomly taken to measure height and ground diameter. ANOVA was used to test the effect of herbaceous species and $R_{\mathrm{s} / \mathrm{h}}$ on the growth of $A$. fruticosa where T0 was used as control. Normality of samples was tested before the significance test, and when the effect was significant $(P<0.05)$ Least Significant Difference
Test (LSD) was used to test comparisons among different seed mixture designs. Statistic analysis was performed using SPSS program.

\section{Results}

\subsection{The effect of species on total coverage}

As shown in Fig. 2, from July to October 2013, T4 had the highest total coverage, regardless of the ratio of shrub to herbaceous seeds. The performance of other seed mixtures differed with time. In July, when $R_{\mathrm{s} / \mathrm{h}} \mathrm{S}$ were $1: 9,3: 7,4: 6$ and $5: 5, \mathrm{~T} 2$ had the second highest total coverage, and when $R_{\mathrm{s} / \mathrm{h}}$ S were $2: 8,6: 4,8: 2$ and $9: 1$, T3 had the second highest total coverage. $\mathrm{T} 1$ had the lowest total coverage in July. From August to October, when $R_{\mathrm{s} / \mathrm{h}} \mathrm{s}$ were $1: 9-3: 7$, T2 had a higher total coverage than $\mathrm{T} 1$, and when $R_{\mathrm{S} / \mathrm{h}} \mathrm{S}$ were $6: 4$ 9: 1, T1 had a higher total coverage value than T2. T3 had a relatively low total coverage from August to October, which was also shown in $\mathrm{T} 2 \mathrm{t} 8$ and $\mathrm{T} 2 \mathrm{t} 9$.

\subsection{The effect of $R_{\mathrm{s} / \mathrm{h}}$ on total coverage}

As shown in Fig. 3, $R_{\mathrm{s} / \mathrm{h}}$ had different effects on the dynamics of total coverage in different species combination.

1. T0: A. fruticosa took a longer time to form a fair coverage and maintained a fair or good coverage for a much shorter period compared to herbaceous species. Total 


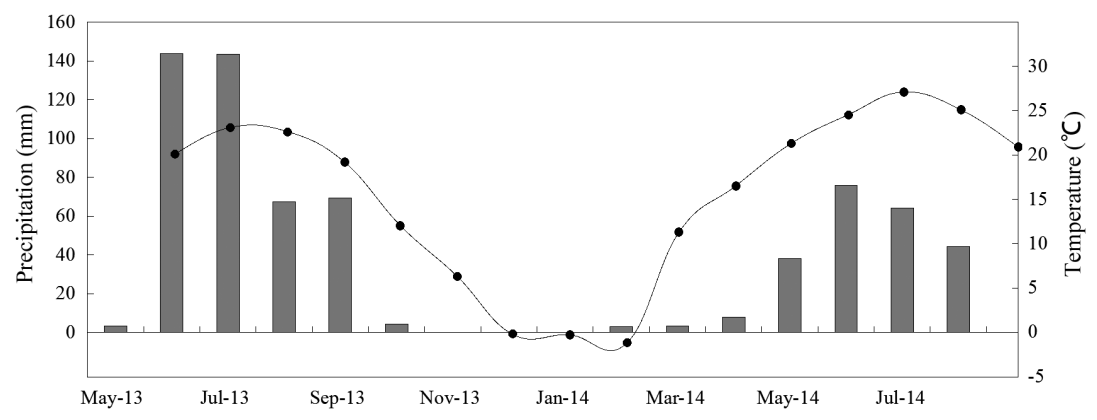

Figure 1. Monthly precipitation (bars) and average temperature (dots) during the experimental period.

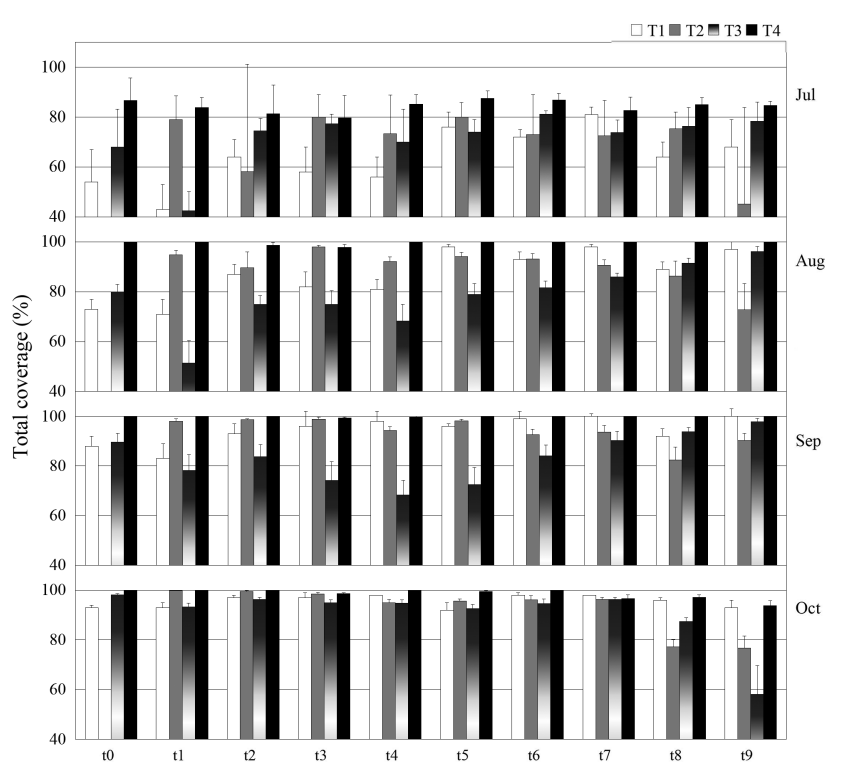

Figure 2. Total coverage of different combinations of shrub and herbaceous seeds $( \pm$ SE) from July to October 2013; see Table 3 caption for code identification.

coverage of T0 was lower than $60 \%$ in July and October but higher than $80 \%$ in August and September.

2. T1: in July, 6 out of 10 plots including t 2 and t5-t9 had a total coverage higher than $60 \%$, among which $\mathrm{t} 7 \mathrm{had}$ a total coverage higher than $80 \%$. In August, except for t0 and $\mathrm{t} 1$, all plots had a total coverage higher than $80 \%$. From September onward, all plots had a total coverage higher than $80 \%$.

3. T2: in July, 7 out of 9 plots including $\mathrm{t} 1$ and $\mathrm{t} 3-\mathrm{t} 8 \mathrm{had}$ a total coverage higher than $60 \%$, among which $\mathrm{t} 3$ and t5 had a total coverage higher than $80 \%$. In August, except for $\mathrm{t} 9$, all plots had a total coverage higher than $80 \%$. From September onward, t1-t7 had a total coverage higher than $80 \%$. The total coverage of $\mathrm{t} 8$ and $\mathrm{t} 9$ was good in September, but both fell to $77 \%$ in October.

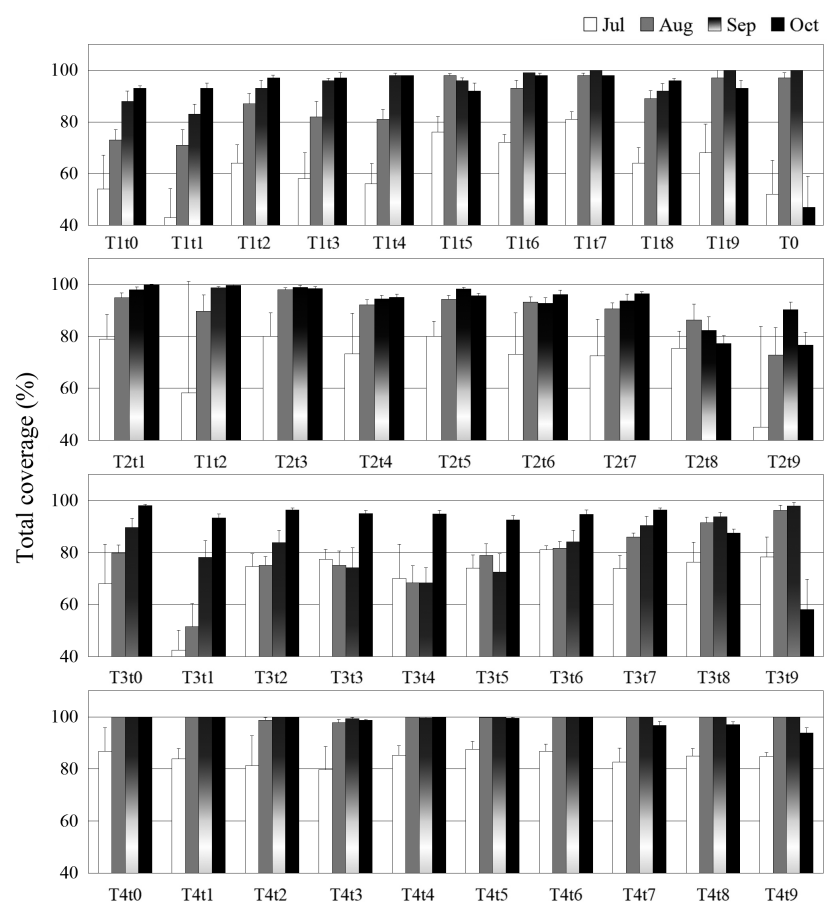

Figure 3. Dynamics of total coverage $( \pm S E)$ from July to October 2013; see Table 3 caption for code identification.

4. T3: in July, 9 out of 10 plots including to and t2-t9 had a total coverage higher than $60 \%$, among which t6 had a total coverage higher than $80 \%$. In August, all plots had a total coverage higher than $60 \%$, among which t0 and $\mathrm{t} 6 \mathrm{-t} 9 \mathrm{had}$ a total coverage higher than $80 \%$. The total coverage of most plots was maintained until October except for $\mathrm{t} 2$, which enhanced total coverage from September, $\mathrm{t} 1$ and $\mathrm{t} 3-\mathrm{t} 5$, which enhanced total coverage in October, and $\mathrm{t} 9$, which decreased total coverage to a value lower than $60 \%$ in October.

5. T4: since July, all plots achieved a total coverage higher than $80 \%$. 


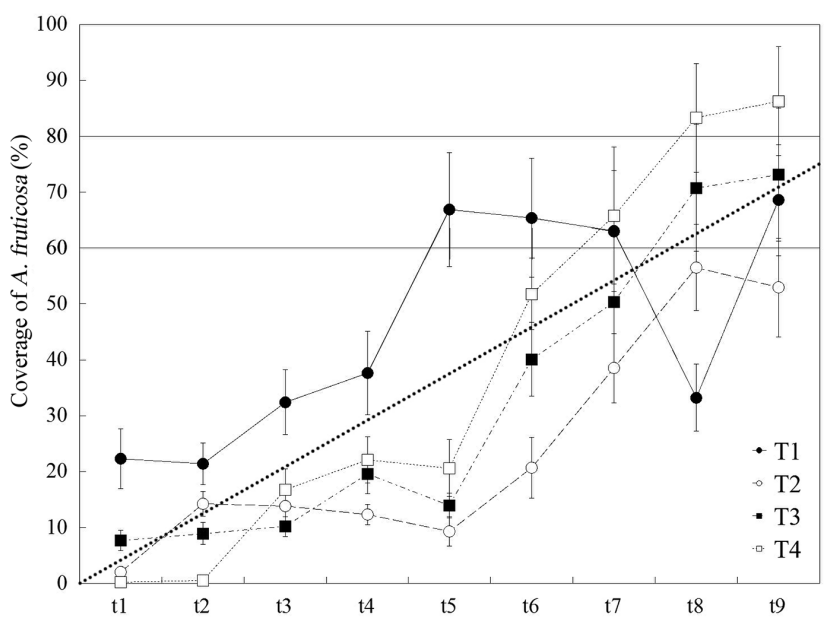

Figure 4. Coverage of A. fruticosa sowed with different herbaceous seeds. Note: each spot with an error bar is the mean value of coverage of $A$. fruticosa during the experimental period. The dotted line indicates a predicted coverage of $A$. fruticosa under different seeding densities based on the assumption that the coverage is proportional to the amount of seeds sowed.

\subsection{Duration and stability of total coverage}

From July to October (counted as 120 days), duration of fair coverage was $76,107,112,112$ and 120 days (mean values of different $R_{\mathrm{s} / \mathrm{h}} \mathrm{S}$, the same below) from T0 to T4, respectively. Duration of good coverage was $65,84,95,82$ and 109 days from T0 to T4, respectively. In this respect, T4 had the best performance, followed by $\mathrm{T} 2, \mathrm{~T} 3, \mathrm{~T} 1$ and $\mathrm{T} 0 . \mathrm{T} 1$ and $\mathrm{T} 3$ had relatively poor performance compared to T4 and T2, but T1t5, T1t7, T3t7 and T3t8 maintained a good coverage of more than 100 days. Even though T2 had the second best performance in general, $\mathrm{T} 2 \mathrm{t} 2$ and $\mathrm{T} 2 \mathrm{t} 9$ maintained a shorter period of fair or good coverage compared to T1 or T3 of the same $R_{\mathrm{s} / \mathrm{h}}$. Remarkably, when $R_{\mathrm{s} / \mathrm{h}}$ was $6: 4$ and $7: 3$, all combinations of shrub and herbaceous seeds maintained a fair coverage for 120 days, i.e., the whole experimental period. As a result, this ratio of shrub to herbaceous seeds is proposed for seed mixtures applied in rapid revegetation.

T0 not only had the shortest duration of fair or good coverage but also had the highest coefficient of variation (46\%), indicating that it had the least stability among all plots. The coefficient of variation from T1 to T4 were 19, 15, 19 and $9 \%$, respectively. The coefficient of variation of T4 was significantly lower than those of T1, T2 and T3 $(P<0.05)$. In T1, plots with a $R_{\mathrm{S} / \mathrm{h}}$ of $5: 5-9: 1$ had a relatively low coefficient of variation, ranging from 10 to $16 \%$. In T2, plots with a $R_{\mathrm{s} / \mathrm{h}}$ of $1: 9$ and $3: 7-8: 2$ had a relatively low coefficient of variation, ranging from 10 to $15 \%$. In T3, plots with a $R_{\mathrm{s} / \mathrm{h}}$ of $2: 8,3: 7,6: 4-8: 2$ had a relatively low coefficient of variation, ranging from 11 to $15 \%$.

\subsection{The effect of herbaceous species on the coverage of A. fruticosa}

The average coverage of $\mathrm{T} 0$ during the experiment period was $74.6 \%$. Assuming the coverage was proportional to the amount of seeds we sowed, some seed mixtures had a positive effect on the coverage of $A$. fruticosa, including T1t1$\mathrm{T} 1 \mathrm{t} 7, \mathrm{~T} 3 \mathrm{t} 8-\mathrm{T} 3 \mathrm{t} 9$ and $\mathrm{T} 4 \mathrm{t} 7-\mathrm{T} 4 \mathrm{t} 9$, while other seed mixtures had a negative effect on the coverage of A. fruticosa, as shown in Fig. 4.

When A. fruticosa was sowed alone, fair coverage was achieved on 30 July. When herbaceous species were sowed with $A$. fruticosa with a $R_{\mathrm{S} / \mathrm{h}}$ range of $1: 9$ to $3: 7$, the coverage of A. fruticosa was lower than $60 \%$ during the whole experimental period in any combination of seed mixtures. When the $R_{\mathrm{S} / \mathrm{h}}$ ranged from $4: 6$ to $7: 3$, the coverage of $A$. fruticosa in T1 reached $60 \%$ first, on 30 August, 20 July, 30 July and 10 August. When the $R_{\mathrm{s} / \mathrm{h}}$ ranged from $8: 2$ to $9: 1$, the coverage of $A$. fruticosa in T4 reached $60 \%$ first, on 20 July. In plots of T1t9, T2t7-T2t9, T3t6-T3t9 and T4t6-T4t7, A. fruticosa also achieved a coverage of $60 \%$ but at a later period of the rainy season.

\subsection{The effect of $R_{\mathrm{s} / \mathrm{h}}$ and herbaceous species on the growth of $A$. fruticosa}

There was a negative effect of herbaceous species on the growth of A. fruticosa, as shown in Table 4. In T1, height growth of $A$. fruticosa was significantly lowered when $R_{\mathrm{S} / \mathrm{h}} \mathrm{S}$ were $1: 9-3: 7$ and $6: 4-8: 2$, while ground diameter was significantly lowered when $R_{\mathrm{s} / \mathrm{h}} \mathrm{S}$ were $1: 9,2: 8$ and $7: 3$ compared to T0. In T2, height and diameter growth of $A$. fruticosa were significantly decreased in all $R_{\mathrm{S} / \mathrm{h}} \mathrm{s}$ compared to T0. In T3, height growth of A. fruticosa was significantly lower than $\mathrm{T} 0$ in all $R_{\mathrm{S} / \mathrm{h}} \mathrm{S}$, while ground diameter was significantly lower than T0 when $R_{\mathrm{s} / \mathrm{h}} \mathrm{S}$ were $2: 8-6: 4$ and $9: 1$. In T4, height growth of A. fruticosa was significantly lowered when $R_{\mathrm{S} / \mathrm{h}}$ s were $3: 7-5: 5$ and $7: 3$, while ground diameter was significantly lowered when $R_{\mathrm{S} / \mathrm{h}}$ was $4: 6$, compared to T0.

When different combinations of species with the same $R_{\mathrm{S} / \mathrm{h}}$ were compared (T1-T4), the values of height and ground diameter were the highest in $\mathrm{T} 3$ when the $R_{\mathrm{S} / \mathrm{h}} \mathrm{S}$ were $1: 9$ and $2: 8$. When the $R_{\mathrm{s} / \mathrm{h}}$ S were $3: 7-5: 5$, T1 had highest value of height and generally the highest value of ground diameter. When the $R_{\mathrm{s} / \mathrm{h}} \mathrm{S}$ were $6: 4-9: 1$, T4 had the highest values of height and ground diameter.

\subsection{Dynamics of the established plant communities in the subsequent year}

T1 was damaged in 2014 so the data are not reported. As to other plots, in April 2014, T2t1-T2t5, T3t0-T3t8 and T4t0$\mathrm{T} 4 \mathrm{t} 5$ had a total coverage higher than $80 \%$, and T3t9 had a total coverage higher than $60 \%$. In May, except for T2t6 and 
Table 4. Average height and ground diameter of A. fruticosa.

\begin{tabular}{|c|c|c|c|c|c|c|c|c|}
\hline & \multicolumn{4}{|c|}{ Height $(\mathrm{cm})$} & \multicolumn{4}{|c|}{ Ground diameter $(\mathrm{cm})$} \\
\hline & $\mathrm{T} 1$ & $\mathrm{~T} 2$ & $\mathrm{~T} 3$ & $\mathrm{~T} 4$ & $\mathrm{~T} 1$ & $\mathrm{~T} 2$ & $\mathrm{~T} 3$ & $\mathrm{~T} 4$ \\
\hline $\mathrm{t} 1$ & $34^{*}$ & $30^{*}$ & $35^{*}$ & - & $0.423^{*}$ & $0.431^{*}$ & 0.668 & - \\
\hline $\mathrm{t} 2$ & $31_{\mathrm{A}}^{*}$ & $44_{\mathrm{B}}^{*}$ & $45_{\mathrm{AB}}^{*}$ & - & $0.328_{\mathrm{A}}^{*}$ & $0.672_{\mathrm{B}}^{*}$ & $0.679_{\mathrm{B}}^{*}$ & - \\
\hline $\mathrm{t} 3$ & $52_{\mathrm{A}}^{*}$ & $33_{\mathrm{B}}^{*}$ & $39_{\mathrm{B}}^{*}$ & $49_{\mathrm{A}}^{*}$ & $0.639_{\mathrm{AB}}^{\mathrm{A}}$ & $0.563_{\mathrm{A}}^{*}$ & $0.594_{\mathrm{AB}}^{*}$ & $0.781_{\mathrm{B}}$ \\
\hline $\mathrm{t} 4$ & $65_{\mathrm{A}}^{\mathrm{A}}$ & $35_{\mathrm{B}}^{*}$ & $43_{\mathrm{B}}^{*}$ & $50_{\mathrm{AB}}^{*}$ & 0.807 & $0.594^{*}$ & $0.626^{*}$ & $0.737^{*}$ \\
\hline t5 & $73_{\mathrm{A}}$ & $36_{\mathrm{C}}^{*}$ & $49_{\mathrm{BC}}^{*}$ & $61_{\mathrm{AB}}^{*}$ & $0.795_{\mathrm{A}}$ & $0.515_{\mathrm{B}}^{*}$ & $0.705_{\mathrm{AB}}^{*}$ & $0.834_{\mathrm{A}}$ \\
\hline t6 & $63_{\mathrm{AB}}^{*}$ & $50_{\mathrm{A}}^{*}$ & $55_{\mathrm{A}}^{*}$ & $82_{\mathrm{B}}^{\mathrm{AB}}$ & $0.679 \mathrm{~A}$ & $0.652_{\mathrm{A}}^{*}$ & $0.756_{\mathrm{AB}}^{*}$ & $1.063 \mathrm{~B}$ \\
\hline $\mathrm{t} 7$ & $53_{\mathrm{A}}^{*}$ & $56_{\mathrm{A}}^{*}$ & $66_{\mathrm{AB}}^{*}$ & $73_{\mathrm{B}}^{*}$ & $0.593_{\mathrm{A}}^{*}$ & $0.669_{\mathrm{A}}^{*}$ & $0.853_{\mathrm{B}}$ & $0.889_{\mathrm{B}}$ \\
\hline $\mathrm{t} 8$ & $55_{\mathrm{A}}^{*}$ & $63_{\mathrm{AB}}^{*}$ & $70_{\mathrm{B}}^{*}$ & ${ }^{89} \mathrm{C}$ & $0.715^{\mathrm{A}}$ & $0.687^{*}$ & 0.837 & 0.899 \\
\hline t9 & ${ }^{79} \mathrm{AC}$ & $54_{\mathrm{B}}^{*}$ & $73_{\mathrm{A}}^{*}$ & $93_{C}$ & $0.849 \mathrm{~A}$ & $0.571_{\mathrm{B}}^{*}$ & $0.761_{\mathrm{A}}^{*}$ & $0.858_{\mathrm{A}}$ \\
\hline T0 & \multicolumn{4}{|c|}{92} & \multicolumn{4}{|c|}{0.926} \\
\hline
\end{tabular}

Note: the superscript * indicates a significant difference compared to T0 $(P<0.05)$. The subscript of the same letter or the absence of subscript indicates that the mean values of height or ground diameter in the same row were not significantly different. No A. fruticosa survived in T4t 1 and T4t2, and only five and two individuals of A. fruticosa survived in $\mathrm{T} 2 \mathrm{t} 1$ and $\mathrm{T} 3 \mathrm{t} 1$, respectively.

T3t2-T3t5, all plots had a total coverage higher than $80 \%$. In June, the total coverage of $\mathrm{T} 2 \mathrm{t} 1, \mathrm{~T} 2 \mathrm{t} 5$ and $\mathrm{T} 3 \mathrm{t} 0-\mathrm{T} 3 \mathrm{t} 5 \mathrm{de}-$ creased and was lower than $60 \%$ because of the wilting of O. Violaceus since April.

Since May, T0 and all plots of T4 achieved a total coverage higher than $80 \%$. Since July, all plots of T2 achieved a total coverage higher than $80 \%$. In August, T3t0-T3t1 had a total coverage ranging from 70 to $73 \%$, while the other plots of T3 achieved a total coverage higher than $80 \%$.

\section{Discussion}

\subsection{The effect of species selection and $R_{\mathrm{s} / \mathrm{h}}$ on total coverage}

Vegetation cover is one of the main factor controlling the effect of soil protection from wind and water erosion (Ferreira and Panagopoulos, 2014). An early recovery of vegetation cover can prevent water erosion during the rainy season, while the stubble and litters can prevent wind erosion during the following dry season. Two months after sowing, total coverage of T0, T1t0, T1t1, T1t3, T1t4, T2t2, T2t9 and T3t1 were lower than $60 \%$, so they are not proposed for rapid revegetation.

Based on the speed and the stability of coverage, sowing seed mixtures performed better than sowing shrubs alone, which was consistent with Gilardelli et al. (2013). Among the combinations of shrub and herbaceous species, T4 showed its excellency in fast ground cover formation and high coverage maintenance around the whole experimental period, most attributed to V. philippica. According to our results, sowing $V$. philippica with a seeding rate of $1.5 \mathrm{~g} \mathrm{~m}^{-2}$ is efficient in rapid revegetation in northern China or regions where the climate and soils are similar. A higher seeding rate may be a waste of seeds and more seriously, the dense ground cover may hinder the recolonization of other native species. In plots where $O$. violaceus instead of $V$. philippica was sowed with A. fruticosa, a coexistence with local annual or perennial herbs such as Bidens pilosa L., Acalypha australis L., Amaranthus retroflexus L., Euphorbia humifusa Willd., Abutilon theophrasti Medic., Artemisia annua L., Convolvulus arvensis L. and Polygonum lapathifolium L. was observed but not in $\mathrm{T} 4$.

Other than T4, T2 had a fast cover formation when $R_{\mathrm{S} / \mathrm{h}}$ was low, and T3 had a fast cover formation when $R_{\mathrm{S} / \mathrm{h}}$ was high. Sowing $F$. arundinacea alone was not appropriate for rapid revegetation because it covered the ground slowly. But considering the whole experimental period, T1 had a relatively high total coverage when $R_{\mathrm{s} / \mathrm{h}}$ was high. As a result, $F$. arundinacea should be mixed with other fast-growing species and a seeding rate of $1.5-6.0 \mathrm{~g} \mathrm{~m}^{-2}$ is proposed in order to achieve high value of total coverage. T3, i.e., $O$. violaceus, covered soil rapidly but had the lowest total coverage considering the whole experimental period. Because $O$. violaceus wilted when the seeds were ripe, a significant decline of $O$. violaceus was observed, though total coverage was hardly affected thanks to the development of $A$. fruticosa.

Before the experiment, we supposed that the stability of total coverage was correlated with the tolerance to environmental stress. For example, because of the stochastic nature of precipitation, wilting, defoliation or die off during water deficiency may weaken the protective effect of vegetation when a rain storm finally occurs (Zuazo and Pleguezuelo, 2008). Compared to herbs, woody species were supposed to maintain a more stable coverage because they could use the resource in the deep soil layers or at least they have longer life (Wang et al., 2005). Contrary to expectation, results showed that $\mathrm{T} 0$ had the highest coefficient of variation among all plots. If $A$. fruticosa could use the water stored in the deep 
layers, its coverage would not fluctuate in spite of the temporal water deficiency (the longest interval between rainfall events was 17 days during our experiment), and thus the coefficient of variation would be small. The high value of coefficient of variation in $\mathrm{T} 0$ indicated that the ability to conserve water and the resistance against environmental stress was not fully developed in A. fruticosa.

Some plots, including T2t2, T2t9 and T3t1, had a low total coverage, and no pattern was observed between these plots and the adjacent plots. It was supposed that random factors such as the variation of seeds and microsite conditions accounted for the poor performance of these plots. However, natural ecosystems are much more diverse than our study plots. Microsites are spatially heterogeneous, weather events are stochastic by nature and the inter- or intraspecific relationship may vary in different stages of individual development and community succession (Zanini et al., 2006). To deal with the spatial and temporal heterogeneity, more species should be used in artificial revegetation because of their adaptation to different niches and thus the reconstruction of the whole plant community is more likely to succeed even if some species fail (Sheley and Half, 2006).

\subsection{The effect of herbaceous species on the growth of shrub}

The coverage of $A$. fruticos $a$ in $\mathrm{T} 1 \mathrm{t} 5, \mathrm{~T} 4 \mathrm{t} 8$ and $\mathrm{T} 4 \mathrm{t} 9$ reached $60 \% 10$ days earlier than $\mathrm{T} 0$, even though fewer seeds were sowed in these plots, indicating a positive effect of herbaceous species on the coverage of $A$. fruticosa. Compared to T0, the average coverage of $A$. fruticosa during the study were higher in T1t1-T1t7, T3t8-T3t9 and T4t7-T4t9, but average height and ground diameter were lower in these plots, indicating that the individuals were smaller, but the number of individuals was higher when herbaceous species were sowed together. The result was consistent with the research by Mason et al. (2013), which showed that ground cover was favorable for shrub germination but disadvantageous to growth. Moreover, when a field study was made in May 2014, it was observed that the stem number of each individual of $A$. fruticosa ranged from three to five in T0, but more than six in $\mathrm{T} 1 \mathrm{t} 9$ and $\mathrm{T} 4 \mathrm{t} 9$, which may partly account for the inconsistency between high coverage and low growth in these plots.

Competition for resources, such as water, may explain the decline of growth of A. fruticosa. Soil water content is determined by the input, such as precipitation and irrigation, together with the output, such as infiltration and evapotranspiration. Plants can increase infiltration rate (Ji et al., 2008) and water holding capacity but also consume a large amount of water during transpiration. As a result, soil water content may be increased or decreased by coexisting species (Bréda et al., 1995, D'Odorico et al., 2007). Competition may also exist for nutrition or light, but the relationship differs among different species (Denslow et al., 2006; Mendoza-Hernández et al., 2014). Research indicated a very comprehensive relationship between different coexisting species; not only negative but also positive relationships were shown in different studies (Harmer et al., 2011, Ballesteros et al., 2012; Zhang et al., 2013; Oliveira et al., 2014).

Other than interspecific competition, intraspecific competition exists. Competition for light between individuals of $A$. fruticosa was more intense in T0 than other plots, especially when $R_{\mathrm{S} / \mathrm{h}}$ was low. In T0, short and weak individuals may be weeded out and only the tall and strong ones which have access to light survive, leading to a higher mean value of growth. Compared to height, ground diameter was less correlated to the competition for light, so it was also less corrected to $R_{\mathrm{S} / \mathrm{h}}$. However, this hypothesis needs to be tested.

\section{Conclusions}

Firstly, shrub cover was formed slower than ground cover and was maintained for a shorter period at least in the early stage of development. When herbaceous species were sowed with shrubs, total coverage increased and was maintained for a longer period, but the growth of shrubs was hindered. Secondly, in the practice of rapid revegetation in the North China Plain or wherever the soil and climate are similar, the ratio of shrub to herbaceous seeds is proposed to be $6: 4-7: 3$ by mass. Thirdly, herbaceous species have different traits. In our experiment, three different types of herbs were found, i.e., slow-growing stable species (F. arundinacea), fast-growing unstable species $(O$. violaceus $)$ and fast-growing stable species (V. philippica). Slow-growing stable species and fast-growing unstable species should not be used alone because they cannot cover the ground fast or they cannot maintain a long period of coverage. A small seeding rate of fast-growing stable species should be used to ensure a fair coverage against erosion, and other species with different traits should be added to enhance the stability of plant community. Fourthly, in the practice of rapid revegetation in the North China Plain or wherever the soil and climate are similar, seeding density of $F$. arundinacea is proposed to be lower than $6 \mathrm{~g} \mathrm{~m}^{-2}$ and the seeding density of $V$. philippica is proposed to be $1.5 \mathrm{~g} \mathrm{~m}^{-2}$.

Acknowledgements. This work was supported by the Major Science and Technology Project in Shanxi Province - Research and Demonstration of Environment Monitoring and Ecological Restoration Technology in Industrial and Mining Areas (20121101009_07).

Edited by: A. Jordán

\section{References}

Abe, T., Yasui, T., Yokoya, M., and Knapp, M.: Regaining habitats from invasive weeds by planting limited-recruitment endemic 
trees on an oceanic island: successes and failures 11 years later, J. For. Res.-Jpn., 20, 135-142, doi:10.1007/s10310-014-0469-7, 2015.

Ballesteros, M., Cañadas, E. M., Foronda, A., Fernández-Ondoño, E., Peñas, J., and Lorite, J.: Vegetation recovery of gypsum quarries: short-term sowing response to different soil treatments. Appl. Veg. Scie., 15, 187-197, 2012.

Borrelli, P., Panagos, P., Ballabio, C., Lugato, E., Weynants, M., and Montanarella, L.: Towards a pan-European assessment of land susceptibility to wind erosion, Land Degrad. Dev., doi:10.1002/ldr.2318, 2014.

Bréda, N., Granier, A., and Aussenac, G.: Effects of thinning on soil and tree water relations, transpiration and growth in an oak forest (Quercus petraea (Matt.) Liebl.), Tree Physiol., 15, 295306, 1995.

Brotons, J. M., Díaz, A. R., Sarría, F. A., and Serrato, F. B.: Wind erosion on mining waste in southeast Spain, Land Degrad. Dev., 21, 196-209, 2010.

Cai, Q.-G.: Soil erosion and management on the Loess Plateau, J. Geogr. Sci., 11, 53-70, 2001.

Denslow, J. S., Uowolo, A. L., and Hughes, R. F.: Limitations to seedling establishment in a mesic Hawaiian forest, Oecologia, 148, 118-128, 2006.

D’Odorico, P., Caylor, K., Okin, G. S., and Scanlon, T. M.: On soil moisture-vegetation feedbacks and their possible effects on the dynamics of dryland ecosystems, J. Geophys. Res.-Biogeo. (2005-2012), 112, G04010, doi:10.1029/2006JG000379, 2007.

Ferreira, V. and Panagopoulos, T.: Seasonality of Soil Erosion Under Mediterranean Conditions at the Alqueva Dam Watershed, Environ. Manage., 54, 67-83, 2014.

Franklin, J. A., Zipper, C. E., and Burger, J. A., Skousen, J. G., and Jacobs, D. F.: Influence of herbaceous ground cover on forest restoration of eastern US coal surface mines, New Forest, 43, 905-924, 2012.

Gilardelli, F., Sgorbati, S., Citterio, S., Gentili, R.: Restoring limestone quarries: hayseed, commercial seed mixture or spontaneous succession?, Land Degrad. Dev., 25, doi:10.1002/ldr.2244, 2013.

Gordon, D. R., Menke, J. M., and Rice, K. J.: Competition for soil water between annual plants and blue oak (Quercus douglasii) seedlings, Oecologia, 79, 533-541, 1989.

Haritash, A. K., Baskar, R., Sharma, N., and Paliwal, S.: Impact of slate quarrying on soil properties in semi-arid Mahendragarh in India, Environ. Geol., 51, 1439-1445, 2007.

Harmer, R., Morgan, G., and Beauchamp, K.: Restocking with broadleaved species during the conversion of Tsuga heterophylla plantations to native woodland using natural regeneration, Eur. J. For. Res., 130, 161-171, 2011.

Heneghan, L., Miller, S. P., Baer, S., Callaham, Jr. M. A., Montgomery, J., Pavao-Zuckerman, M., Rhoades, C. C., and Richardson, S.: Integrating Soil Ecological Knowledge into Restoration Management, Restor. Ecol., 16, 608-617, 2008.

Houyou, Z., Bielders, C. L., Benhorma, H. A., Dellal, A., and Boutemdjet, A.: Evidence of strong land degradation by wind erosion as a result of rainfed cropping in the Algerian steppe: a case study at Laghouat, Land Degrad. Dev., doi:10.1002/ldr.2295, 2014.
Huang, Z.-L., Chen, L.-D., Fu, B.-J., Lu, Y.-H., Huang, Y.-L., and Gong, J.: The relative efficiency of four representative cropland conversions in reducing water erosion: evidence from long-term plots in the Loess hilly area, China, Land Degrad. Dev., 17, 615627, 2006.

Ji, Z.-H., Liao, C.-F., Yang, Y.-X., Fang, H. D., Pan, Z.-X., and Sha, Y.-C.: Vegetation Restoration Technique System and Its Ecological Functions of the Degraded Ecosystem in the Arid-Hot Valleys-Taking the Example of Typical Mode in Small Watershed of Yuanmou, Wuhan University Journal of Natural Sciences, 13, 257-266, 2008.

Ji, S.-X., Liu Y.-T., Dong Z., Li, H.-L., and Liu, Z.: Variations of Wind Erosion and Soil Physicochemical Properties in Artificial Afforestation with Different Years in Yellow River Flood Plain, Res. Soil Water Conserv., 18, 158-161, 2011.

Jim, C. Y.: Ecological and Landscape Rehabilitation of a Quarry Site in Hong Kong, Restor. Ecol., 9, 85-94, 2001.

Kefi, M., Yoshino, K., Setiawan, Y., Zayani, K., and Boufaroua, M.: Assessment of the effects of vegetation on soil erosion risk by water: a case of study of the Batta watershed in Tunisia, Environmental Earth Sciences, 64, 707-719, 2011.

Leenders, J. K., van Boxel J. H., and Sterk, G.: The effect of single vegetation elements on wind speed and sediment transport in the Sahelian zone of Burkina Faso, Earth. Surf. Proc. Land., 32, 1454-1474, 2007.

Liang, S.-J.: Study on the Suitability of River Ecological Slope Protection Measures in North China Plain Region, Beijing Forestry University, 2013.

Mason, T. J., French, K., and Jolley, D.: Arrival order among native plant functional groups does not affect invasibility of constructed dune communities, Oecologia, 173, 557-568, 2013.

Maurer, T., Herrmann, L., and Stahr, K. The effect of surface variability factors on wind-erosion susceptibility: A field study in SW Niger, J. Plant. Nutr. Soil. Sc., 172, 798-807, 2009.

Mendoza-Hernández, P. E., Rosete-Rodríguez, A., SánchezCoronado, M. E., Orozco, S., Pedrero-López, L., Méndez, I., and Orozco-Segovia, A.:Vegetation patches improve the establishment of Salvia mexicana seedlings by modifying microclimatic conditions, Int. J. Biometeorol., 58, 853-866, 2014.

Milton, S. J. and Dean, W. R. J.: South Africa's arid and semiarid rangelands, why are they changing and can they be restored?, Environ. Monit. Assess., 37, 245-264, 1995.

$\mathrm{Mu}, \mathrm{Q}$ : Effect of nonerodible grains on wind erosion control, J. Geophys Res.-Atmos, 115, D21103, doi:10.1029/2010JD014221, 2010.

Oliveira, G., Clemente, A., Nunes, A., and Correia, O.: Suitability and limitations of native species for seed mixtures to revegetate degraded areas, Appl. Veg. Sci., 17, 726-736, 2014.

Robbins, J. C., Petterson, M. G., Mylne, K., and Espi, J. O.: Tumbi Landslide, Papua New Guinea: rainfall induced?, Landslides, 10, 673-684, 2013.

Sheley, R. L. and Half, M. L.: Enhancing Native Forb Establishment and Persistence Using a Rich Seed Mixture, Restor. Ecol., 14, 627-635, 2006.

Sterk, G.: Causes, consequences and control of wind erosion in Sahelian Africa: a review, Land Degrad. Dev., 14, 95-108, 2003.

Vrieling, A., Sterk, G., and Vigiak, O.: Spatial evaluation of soil erosion risk in the West Usambara Mountains, Tanzania, Land Degrad. Dev., 17, 301-319, 2006. 
Wang, Z.-Y., Wang, G.-Q., Li, C.-Z., and Wang, F.-X.: A preliminary study on vegetation-erosion dynamics and its applications, Sci. China Ser. D., 48, 689-700, 2005.

Wei, W., Chen, L., Fu, B., Lü, Y.-H., and Gong, J.: Responses of water erosion to rainfall extremes and vegetation types in a loess semiarid hilly area, NW China, Hydrol. Process., 23, 1780-1791, 2009.

Zanini, L., Ganade, G., and Hübel, I.: Facilitation and competition influence succession in a subtropical old field, Plant Ecol., 185, 179-190, 2006.
Zhang, H. and Shao, X.: Improving agroforestry in sandy subhumid northwestern Shandong, China, Land Degrad. Dev., 14, 421-429, 2003.

Zhang, H., Zhuang, X.-Y., and Chu, L.-M.: Plant recruitment in early development stages on rehabilitated quarries in Hong Kong, Restor. Ecol., 21, 166-173, 2013.

Zhang, X., Yu, G.-Q., Li, Z.-B., and Li, P.: Experimental Study on Slope Runoff, Erosion and Sediment under Different Vegetation Types, Water Resour. Manag., 28, 2415-2433, 2014.

Zuazo, V. H. D. and Pleguezuelo, C. R. R.: Soil-erosion and runoff prevention by plant covers. A review, Agron. Sustain. Dev., 28, 65-86, 2008 